\title{
TeOlOGiA EM Foco: réplicas linguístico-axiológico-discursivas de Jesus ao ceticismo judaico no primeiro século da era cristã
}

\author{
THEOLOGY IN FOCUS: \\ linguistic-axiological-discoursive replies of Jesus \\ to jewish skepticism in the first century christian age
}

Wilder Kleber Fernandes de Santana *

\begin{abstract}
RESUMO
Este trabalho delimita como objeto de estudo algumas réplicas de Jesus Cristo presentes no relato do evangelista João, capítulo 5 (edição revista e ampliada (2002) - Bíblia de Jerusalém), especificamente no primeiro século da era cristã. Com base nos estudos bakhtinianos, realizamos a análise discursiva a partir de duas categorias: axiologia e heterodiscursividade. Elencamos o Discurso de Jesus sobre o ceticismo judaico como o escopo arquitetônico da narrativa joanina por haver marcadamente múltiplas vozes atravessando os dizeres do enunciador. É uma análise de cunho bibliográfico, em que os resultados demonstram que o sujeito dialógico-enunciativo ocupa lugar em determinado espaço social, incidindo sobre a constituição através do posicionamento responsivo ativo no processo de enunciação.
\end{abstract}

Palavras-chave: Axiologia. Heterodiscursividade. Jesus Cristo.

\begin{abstract}
This paper delimits as object of study some replicas of Jesus Christ present in the account of the evangelist John, chapter 5 (revised and expanded edition (2002) - Jerusalem Bible), specifically in the first century christian age. Based on the Bakhtinian studies, we conducted the discursive analy sis from two categories: axiology and heterodiscursivity. We have listed Jesus' Discourse on Jewish Skepticism as the architectural scope of the Johannine narrative because there are markedly multiple voices going through the utterances of the enunciator. It is a bibliographical analysis, in which the results demonstrate that the dialogicenunciative subject occupies place in a certain social space, focusing on the constitution through the active responsive positioning in the process of enunciation.
\end{abstract}

Keywords: Axiology. Heterodiscursivity. Jesus Christ.

\section{INTRODUÇÃO}

Este trabalho traça como horizonte analítico as réplicas realizadas sobre o ceticismo judaico, pelo sujeito enunciativo Jesus Cristo, no instante em que estava sendo perseguido por seus interlocutores, os judeus. Nosso intuito é perceber, a partir

\footnotetext{
* Mestre em Teologia pela Faculdade Teológica Nacional (FTN) e graduado em Letras-Português pela Universidade Federal da Paraíba (UFPB). Atualmente, doutorando em Linguística também na UFPB e bolsista CAPES. E-mail: wildersantana92@gmail.com
} 
da Teoria Dialógica da Linguagem, formulada por Bakhtin e o Círculo, as réplicas linguístico-axiológico-discursivas manifestas na enunciação do expositor.

A versão bíblica que se adotou como fulcro e referência para a composição deste trabalho foi a Bíblia de Jerusalém ${ }^{1}$ (2002), cujos direitos são certificados pela Paulus Editora. Nesta Nova Edição Revista e Ampliada, a tradução realizada imerge nos textos originais (hebraico e grego).

A Paulus Editora propôs nova elaboração funcional bíblica, o que corporifica o histórico de revisões que esta tradução teve desde 1973 até 1998, mediante os trabalhos da École Biblique. Após ter passado por um longo processo de revisão e por estudos intensos e revisões severas, em termos semântico-discursivos, a versão Bíblia de Jerusalém contém algumas expressões presentes no evangelho de João, especificamente o capítulo seis, que se tornam essenciais para que se compreenda a autoridade com que se revestiu Jesus em suas enunciações/réplicas, a exemplo de: “Trabalhai, não pelo alimento que se perde, mas pelo alimento que permanece até a vida eterna” (6.27); “A obra de Deus é que creiais naquele que ele enviou” (6.29); “Eu, porém, vos disse: vós me vedes, mas não credes." (6.36).

Corroboramos a afirmação de Volochínov, para quem “A palavra é uma ponte que liga o eu ao outro. Ela apoia uma das extremidades em mim e a outra no interlocutor." (VOLOCHÍNOV 2017 [1929], p. 205). Assim, todo e qualquer texto, seja ele verbal ou não-verbal, tem uma natureza social interativa, pois quem o produz tem uma intenção comunicativa. Como afirma Bakhtin (2006 [1979], p. 282), “A vontade discursiva do falante realiza-se antes de tudo na escolha de um certo gênero de discurso.”

Nesse sentido, é em aprofundamento a um projeto de investigação dos discursos humanos e da interação no processo de comunicação que surge(m) o(s) conceito(s) de dialogismo, para Bakhtin. De acordo com este teórico,

\footnotetext{
1 Em 1973, a Paulus Editora (outrora Edições Paulinas), empreendeu o exercício de traduzir, para o público brasileiro, a versão Bíblia de Jerusalém, considerada em diversos países a melhor edição desta escritura. Exegetas católicos e protestantes passaram três anos em trabalho intensivo de revisão, e primeiramente foi concretizada a tradução do Novo Testamento. É então que, em 2002, a Paulus Editora, servindo-se da edição revista e ampliada, publica novo texto bíblico.
} 
A orientação dialógica é naturalmente um fenômeno próprio a todo o discurso. Trata-se da orientação natural a qualquer discurso vivo. Em todos os seus caminhos até o objeto, em todas as direções, o discurso se encontra com o discurso de outrem e não pode deixar de participar, com ele, de uma interação viva e intensa. (BAKHTIN, 2010 [1930-1934], p. 88).

É pertinente imprimir que Bakhtin, considerado "o pensador mais impressionantemente produtivo nas Ciências Humanas a emergir na Rússia soviética e um dos mais significativos teóricos da literatura no século XX" (RENFREW, 2017, p. 13) tem enriquecido (a exemplo da teoria cronotópica) pensamentos e influenciado horizontes múltiplos do saber, tais como Fenômenos de cognição em literatura (KEUNEN, 2000), Teologia e Literatura (SANTANA, 2016; 2017), Narratologia (SCHOWLZ, 2003), estudos em Autoria (FRANCELINO, 2007) e a Teoria da recepção (COLLINGTON, 2006).

A base teórica escolhida para esse trabalho orienta-se para uma concepção de discurso que considera as características de axiologia e heterodiscursividade. Uma das particularidades presentes neste é o dialogismo, o qual delimita a construção de valores enunciativos existentes em prol de serem resposta ativa e necessária. Desse modo, subsidiam nossas análises as propostas teóricas de Bakhtin (2006 [1979], 2010 [1924], 2015, 2016 [1979]), Volóchinov (2017 [1929]), Medviédev (2016 [1928]) e alguns interlocutores como Ponzio (2008), Santana (2014, 2015, 2017) e Renfrew (2017).

Elencamos o Discurso de Jesus sobre o ceticismo judaico como o escopo arquitetônico da narrativa joanina compreendido entre os versos 44 e 47 de seu escrito evangelístico, capítulo quinto.

Falamos aqui de Ceticismo na perspectiva discursiva de Champlin (2014, p. 705), o qual transcende os limites etimológicos do termo (do gr. Skepsis), e o agencia como "Dúvida... a ideia de que a razão, as percepções e os outros meios que podem ser utilizados para alcançar o conhecimento são fracos, enganadores e inadequados para este fim, se o conhecimento foi considerado uma coisa perfeita, fixa ou completa.”. Em outras palavras, o ceticismo caracteriza-se pelo posicionamento de desconfiança e dúvida diante do que se diz e não foi cientificamente comprovado, é quando um grupo específico (ou até mesmo uma pessoa) descrê, por não haver provas materiais. 
A pesquisa é de caráter bibliográfico e documental e o corpus constitui-se de 4 (quatro) versículos bíblicos relatados por João, em seu evangelho, acerca de palavras de Jesus Cristo. Nesse discurso, percebem-se as diferentes formas de presença do outro, ou seja, presença de diversas vozes sociais, e as réplicas são resultantes de relações interdiscursivas. Trata-se, portanto, de uma pesquisa de cunho qualitativointerpretativo. Utilizaremos como abordagens teóricas as reflexões de Bakhtin, Volochínov e Medviédev sobre a noção de dialogismo, bem como algumas pressuposições sobre axiologia e discurso.

\section{A CONCEPÇÃO DIALÓGICA DE LINGUAGEM PARA BAKHTIN}

A língua, em seu vivenciamento empático, e em sua totalidade concreta, tem propriedade de ser dialógica. Desse modo, quando reportamos nossa centralidade para o(s) sujeito(s) dialógico(s), compreendemos que seus discursos só existem na forma de enunciações concretas, por serem constitutivamente os sujeitos do discurso. Para Santana,

Os enunciados concretos, como unidade real da comunicação, ocorrem a partir da alternância dos sujeitos dos discursos, isto porque o sujeito termina seu enunciado para passar a palavra ao outro, tornando-se um ser responsável e participativo pelo que enuncia, um agente produtor de sentidos dos discursos produzidos socialmente em situações concretas. (SANTANA, 2014, p. 2)

A orientação dialógica da linguagem constitui a tese central dos escritos (filosóficos, literários e linguísticos) de Bakhtin, Volóchinov e Medviédev, embora cada um desses pensadores tenha se debruçado sobre questões específicas em suas trajetórias de reflexão sobre a linguagem. Em constantes movências translativas, orbitam outras categorias não menos importantes e que são essenciais para a compreensão do funcionamento do discurso em uma comunidade enunciativa, dentre as quais a axiologia, a heterodiscursividade e o tom volitivo-emotivo.

Ao discorrer sobre esse aspecto da linguagem sob a ótica de Bakhtin, Barros (2005) afirma: 
Bakhtin, repetimos, considera o dialogismo o princípio constitutivo da linguagem e a condição do sentido do discurso. Insiste no fato de que o discurso não é individual, nas duas acepções de dialogismo mencionadas: não é individual porque se constrói entre pelo menos dois interlocutores, que, por sua vez, são seres sociais; não individual porque se constrói como um "diálogo entre discursos", ou seja, porque mantém relações com outros discursos. Conciliam-se, assim, nos escritos de Bakhtin, as abordagens do texto ditas "externas" e "internas" e recupera-se, no texto, seu estatuto pleno de objeto linguístico-discursivo, social e histórico (BARROS, p.32).

Para dar suporte à leitura dialógica que faremos, refletimos sobre um conceito fundamental desses escritos, que é o de axiologia, estando relacionados a ele, além de alguns dos já mencionados acima, o de expressividade, entonação avaliativa, endereçamento etc. Segundo Bakhtin (2016, p. 54, grifos nossos),

[...] a experiência discursiva individual de qualquer pessoa se forma e se desenvolve em uma interação constante e contínua com os enunciados individuais dos outros. [...] Nosso discurso, isto é, todos os nossos enunciados (inclusive as obras criadas) é pleno de palavras dos outros, de um grau vário de alteridade ou de assimilabilidade, de um grau vário de aperceptibilidade e de relevância. Essas palavras dos outros trazem consigo a sua expressão, o seu tom valorativo que assimilamos, reelaboramos e reacentuamos.

Esse aspecto do endereçamento que orienta a seleção dos meios para a realização do enunciado está diretamente relacionado ao fato de o enunciado já antecipar, em certa medida, a resposta do outro; é como se, no ato enunciativo, presumíssemos o que o outro dirá, como se objetássemos as respostas do interlocutor e, a partir disso, antecipássemo-nos em nossas formulações, em nossos posicionamentos axiológicos. Essas formulações corroboram a natureza dialógica do discurso e revelam a dimensão alteritária constitutiva dos enunciados que produzimos.

O filósofo russo "oferece um modo de compreender a relação complexa entre texto e mundo com base na presença do(s) sujeito(s) humano(s) sem entrar em complô com teorias cruas, unidimensionais de intencionalidade.” (RENFREW, 2017, p. 15). Assim, averiguamos existir uma pós-teorização nos modos de mobilizar a linguagem, o que se dilui na Teoria do romance: a estilística:

O falante procura orientar sua palavra - e o horizonte que a determina - no horizonte do outro que a interpreta, e entra em relações dialógicas com elementos deste horizonte. $\mathrm{O}$ falante abre caminho para o horizonte alheio do ouvinte, constrói sua enunciação em território alheio, no campo aperceptivo do ouvinte. (BAKHTIN, 2015, p. 55-56). 
Em horizonte isomórfico, a axiologia faz menção às atribuições de valor(es) presentes na obra a partir das dialogizações e réplicas entre autor e personagem. Esta é uma categoria utilizadas por Bakhtin, inicialmente acerca do Ato e dos atos humanos [em processo], sobre sua linguagem. Na perspectiva dialógico-axiológica, a língua, os enunciados, os discursos, não são trabalhados como um sistema de categorias gramaticais abstratas. "Em cada momento concreto da formação discursiva, os enunciados são estetificados em camadas socioideológicas, ou seja, manifestam-se através da história e da memória culturais (processo de estetificação)" (SANTANA, 2017, p. 237). Conforme Santana (2017, p. 240),

A valoração é um elemento importante na obra, em que o autor justapõe responsivamente os enunciados (e todos os outros elementos) à história e à memória ideológica sociais. Esse plano, chamado de axiologicamente valorativo, se faz de modo responsavelmente racional, ou seja, é o ponto nevrálgico em que a obra mantém contato pleno com outras vozes que a atravessam, e aí reside seu valor interdiscursivo.

O valor axiológico que um autor-contemplador pode atribuir a uma obra, ao lê-la, concluí-la, ao delimitá-la com seus tons emotivos-volitivos, é transferir a esse objeto os diálogos existentes em seu interior, ou seja, estabelecer vínculos desta com outras obras/vozes/valorações. O autor não deve vivenciar o objeto para si mesmo, mas sempre pensando que o vivenciamento de uma postura axiológica consiste na presença constitutiva do outro em mim (outros enunciados que atravessam os discursos os quais profiro). (grifos nossos).

Este "valorar" não permanece em níveis literários, mas também é transferido para a esfera ética, em que os seres humanos, na medida em que produzem e proliferam culturalmente seus discursos, operacionalizam gestos axiológicos, constituição múltipla de consciências.

Nesse direcionamento, atribuir-se-á enfoque contínuo à linguagem, não apenas nos seus aspectos estruturais fonomorfossintáticos (componentes fonológicos, morfológicos e sintáticos), mas sobretudo a seus aspectos sócio-históricos e às relações axio(dia)lógicas ${ }^{2}$ constitutivas de múltiplos sentidos e pelos sujeitos que a mobilizam, sendo estes social, histórica e ideologicamente constituídos. Nessa linha interpretativa, Medviédev (2016 [1928], p. 49-50), assevera que

2 A expressão designa tanto relações de ordem dialógica quanto as que condicionam o valorar, ou a axiologia (processamento de valor), categorias bakhtinianas. 
Todos os atos individuais participantes da criação ideológica são apenas os momentos inseparáveis dessa comunicação e são seus componentes dependentes e, por isso, não podem ser estudados fora do processo social que os compreende como um todo. O sentido ideológico, abstraído do material concreto, é oposto, pela ciência burguesa, à consciência individual do criador ou do intérprete... Cada produto ideológico e todo seu "significado ideal" não estão na alma, nem no mundo interior e nem no mundo isolado das ideias e dos sentidos puros, mas no material ideológico disponível e objetivo, na palavra, no som, no gesto, na combinação das massas, das linhas, das cores, dos corpos vivos, e assim por diante.

$\mathrm{Na}$ ótica de Medviédev, não há incidência de ideologia caso exista separabilidade entre o processo cultural (meio sócioideológico) e o objeto. Enquanto signos, jamais enunciados/enunciações podem ser avaliadas longe de sua realidade sócio-histórica, das vozes que os/as atravessam.

Sobre o dirigir-se a outro(s), a interação que estabelecemos com a palavra alheia "nunca é uma relação de equivalência, porque ela é concebida para um terceiro: o destinatário. Existem pelos menos outros dois com quem nos relacionamos ao falar: a pessoa de quem tomo as palavras e a pessoa a quem me dirijo. A relação é... triangular" (PONZIO, 2008, p. 103). Nas vias dessa pavimentação semânticodialógico-discursiva, nos diálogos que se estabelecem para concretização da compreensão responsiva ativa,

[...] sempre levo em consideração o campo aperceptivo da percepção do meu discurso pelo destinatário: até que ponto ele está a par da situação, dispõe de conhecimentos especiais de um dado campo cultural da comunicação; levo em conta as suas concepções e convicções, os seus preconceitos (do meu ponto de vista), as suas simpatias e antipatias - tudo isso irá determinar a sua ativa compreensão responsiva do meu enunciado. (BAKHTIN, 2016, p. 63-64, destaque do autor).

Nesse sentido, Jesus, imbuído de vozes construídas em relações heterodiscursivas geradas na "Lei de Moisés, e nos profetas e nos Salmos". (Lc. 24:44), dirige-se a consciências outras: aos líderes dos judeus. Em expressões bakhtinianas, estamos diante de, no mínimo, duas consciências (2006 [1979]).

Paralelo a isso, reenunciamos as proposições deste filósofo soviético (2006 [1979]), para quem 
cada enunciado é pleno de ecos e ressonâncias de outros enunciados com os quais está ligado pela identidade da esfera de comunicação discursiva. Cada enunciado deve ser visto antes de tudo como uma resposta aos enunciados precedentes de um determinado campo: ela os rejeita, confirma, completa, baseia-se neles, subentendeos como conhecidos, de certo modo os leva em conta. (BAKHTIN, 2006 [1979], p. 297).

Tendo em vista que o marco superlativo das Ciências Humanas foi a inclusão do sujeito na pauta de discussões da linguística desenvolvida nestes últimos 30 anos, nossa pesquisa realiza uma análise linguístico-axiológico-discursiva de versos bíblicos, cujo funcionamento da linguagem ganha corporalidade em ótica pluridimensional. Portanto, incidiremos no ato dialógico de demarcar as fronteiras enunciativas, cujos subsídios teórico-metodológicos circunscreverão o corpus.

\section{O SUJEITO JESUS CRISTO E SEU DISCURSO SOBRE O CETICISMO JUDAICO}

No que concerne ao contexto cronotópico em que se encontrava Jesus Cristo, no momento em que começou a discursar sobre o ceticismo judaico, os registros joaninos apontam que o sujeito, o qual chamavam Mestre, estava próximo à porta das ovelhas, junto aos seus discípulos, quando subiu a Jerusalém, lugar em que ocorrera a cura de um paralítico de Betesda (Jo 5). Devido ao rigor legalista de inatividade em dia de sábado, Jesus começou a ser perseguido pelos judeus3 (Jo 5. 16) por realizar o exercício da cura exatamente neste dia. Por esse motivo, procuravam mata-lo (Jo 5 . 17). Nessas circunstâncias, quando começou o sujeito da enunciação a discursar sobre a importância de os seres humanos dependerem de Deus, com respeito ao Pai, à ressurreição e à glória humana, também adentrou em apontamentos sobre o ceticismo dos judeus, os quais duvidavam do Divino: "V. 44 Como podeis crer, vós

3 Faz-se imprescindível explicar de que judeus estamos falando, uma vez que esse termo faz menção a diversos conjuntos populacionais, na Bíblia. Não nos referimos aos judeus que são descendentes da tribo de Judá (II Reis 16.6), nem tampouco nos referindo aos judeus enquanto todo o povo de Israel que ficou cativeiro na Babilônia e que retornaram à Palestina. Champlin (2014, p. 631) nos explica que, nesse momento, o termo judeus se refere "somente aos seus líderes religiosos, especialmente o partido dos fariseus". Écaracterístico dos registros evangelísticos a exposição de total rejeição, por parte destes líderes, à doutrina que era proferida por Jesus, "os líderes religiosos do povo judeu rejeitaram a Cristo" (CHAMPLIN, 2014, p. 631). 
que recebeis glória uns dos outros, mas não procurai a glória que vem do Deus único?”

Através de réplicas enunciativas por meio de interpelação, Jesus Cristo posiciona-se contra as hipocrisias (Mt. 23) dos judeus, apresentando razões para o fracasso destes últimos. Inicia Jesus o seu discurso indagando aquele grupo judaico sobre a sua crença. Como poderiam acreditar em tudo o que se dizia sobre o Pai, se sua prática demonstrava justamente o contrário, que era prestarem e receberem glória uns dos outros?

A partir de um amplo estudo realizado por Vine et.al (2013, p. 518), "pisteuõ, “crer”, também "ser persuadido de” e, por conseguinte, “por a confiança em; confiar”, significa, nesse sentido de palavra, confiança e não mera crença. É muito frequente nos escritos do apóstolo João sobretudo no Evangelho”. Percebe-se, dessa forma, que a indagação de Jesus é discursivo-axiologicamente retórica, pois traz em si mesma o anúncio de que é impossível os judeus crerem, o que resulta no clímax de seu ceticismo. Então, acerca dessa passagem específica, F. F. Bruce (2011, p. 128) nos esclarece que "o tempo do verbo crer é aoristo (pisteusai, aoristo infinitivo); por isso pode ser que o ato inicial de crer esteja aqui: “Como vocês podem por sua fé (em $\operatorname{mim})$ ?"

Os termos como podeis crer, vós que recebeis glória, nesse sentido, derivam do grego doxa, e ganha novos sentidos com relação à aprovação. Em outras palavras, o enunciado de Jesus soaria como vocês podem aprovar essa atitude de crer uns nos outros? Através dos registros de João, compreende-se que as atitudes dos judeus demonstravam concretamente seu ceticismo em relação a Deus, uma vez que estavam todos os confundidos em sua crença.

Em análise axiológico-discursiva, em percepção dos tons semântico-volitivos, acentuando o elo inexorável entre sujeitos do heterodiscurso, afirma Bakhtin (2015, p.42) que 
Cada enunciação concreta do sujeito do discurso é um ponto de aplicação tanto das forças centrípetas quanto das centrífugas. Nela se cruzam os processos de centralização, unificação e separação, um basta não só a sua língua como materialização discursiva individual como também basta ao heterodiscurso, é seu participante ativo. E essa comunhão ativa de cada enunciado no heterodiscurso vivo determina a feição linguística... O autêntico meio da enunciação, no qual ela se forma e vive, é justamente o heterodiscurso dialogizado, anônimo e social como na língua, mas concreto, rico em conteúdo e acentuado como enunciação individual. (grifos nossos).

Ao nos remetermos às condições de produção éticas do enunciado, teremos acesso às vozes constituintes do discurso. O apóstolo Paulo, em sua carta aos Romanos, afirmara que “...todo aquele que nele crer não será confundido” (Rm 10.11), o que consiste tanto em uma alerta ao auditório eclesiástico de Roma quanto em uma resposta aos judeus, os quais estavam imersos em seus próprios devaneios. João assevera que os judeus "amavam mais a glória dos homens que a glória de Deus” (Jo 12.43), e com isso potencializa os tons axiológicos de seu dizer.

A orquestração de vozes que incide sobre os enunciados de Jesus nos ajuda a compreender os motivos pelos quais os judeus estivessem confundidos: a desobediência. Desde o Antigo Testamento Deus falara muitas vezes sobre as consequências do obedecer/desobedecer, e seus ascendentes procuravam outro caminho. Em um breve percurso bíblico podemos enxergar que Deus enviou o seu terror confundindo a todo o povo (Êx. 23.27), e muitas vezes anunciava antecipadamente (Sl 2.5/ Sl 83.17). Porém, Paulo, em sua carta aos romanos convoca um discurso segundo o qual a Esperança em Deus não confunde ( $\mathrm{Rm}$ 5.5), e todo aquele que crer na Pedra de Sião - representação do próprio Jesus - não será confundido ( $\mathrm{Rm}$ 9. 33).

Então, em meio aos judeus, Jesus continua a discursar: “v. 45 Não penseis que eu vos acusarei diante do Pai; Moisés é vosso acusador, ele, em quem puseste a vossa esperança”. O sujeito enunciador afirma que não realizará acusação sobre os judeus, uma vez que a própria doutrina na qual estão ancorados (nesse caso, Moisés é uma metonímia, é a lei de Moisés, ou Torá) contém requisitos que os condenam4. Percebemos, a partir de uma (in)constante flutuação das enunciações de Jesus, que

\footnotetext{
4 Em uma superfície enunciativa mais profunda,também acerca de julgar, o próprio Jesus declara, a partir da escritura de João, que quem haveria de julgar seria a Palavra (Jo 12, 47 -48) e não ele mesmo (na posição de Pai), porque ao Filho fora dado todo o juízo (Jo 5,22$)$ - através do ato de enunciar e proclamar as escrituras sagradas (a Lei).
} 
este não precisaria acusar aquela massa judaica, apontando os seus erros (pela lei da graça), pois os próprios ensinos mosaicos, que ela carregava em seus discursos, trataria de condená-la.

Na primeira parte do escopo formal (o período), em que se dispõem os versos Não penseis que eu vos acusarei diante do Pai, o termo "Pai" traz consigo toda uma carga heterodiscursiva de autoridade, revestimento de "poder”, liberdade na (re)ação. Jesus, em suas condições específicas de produção do enunciado, na posição de homem/filho em que se encontrava, não precisaria invocar/convocar alguma autoridade do domínio espiritual/metafísico, uma vez que a própria doutrina de seguimento dos judeus iria denunciá-los. “A principal testemunha de acusação seria alguém que eles veneravam profundamente. Moisés, através de quem Deus lhes tinha dado a lei na qual se baseavam... é quem testemunharia contra eles" (BRUCE, 2011, p. 128). Paulo, em carta aos Romanos, conferencia que "Todos os que sob a lei pecaram, sob a lei serão julgados” (Rm 2.12).

É na faísca semântico-dialógica dessa linha expositiva que se coloca a segunda parte da enunciação: Moisés é vosso acusador, ele, em quem puseste a vossa esperança. O fato de os judeus causarem um efeito mútuo de glorificação uns aos outros, numa tentativa de substitutibilidade de Deus, os direcionava a transgredirem a própria lei através da qual se pronunciavam, que lhes servia de argumento pseudofilosófico. Conforme já pontuamos, a expressão Moisés, nesse caso, por representar e significar a Lei dada ao povo de Israel, trata-se de uma metonímia, não apenas porque "consiste em considerarmos o efeito pela causa; o autor pela obra". (ROCHA LIMA, 1996, p. 506), mas sobretudo pela projeção do autor-criador em seu discurso (BAKHTIN, 2010 [1924]).

Bechara (2009, p. 397) nos dirá, acerca dessa figura de linguagem, que "ocorre uma translação de significado pela proximidade de ideias" entre as palavras, "não porque são sinônimas, mas porque uma evoca a outra” (SEGALLA, 2008, p. 202).

Na compreensão de Santana (2015), ao colocar Moisés como figura central diante da falsa crença judaica, $\mathrm{O}$ enunciador reenuncia a arquitetônica da lei mosaica e lança para os judeus: a própria lei como sinônimo de condenação. Assim, Jesus estava reconstruindo uma perspectiva judaico-cristã, reacentuando aspectos existentes no Antigo Testamento. Nessa constelação discursiva, sobre a Lei, 
ao elencá-la, Jesus embebe todo um discurso provindo de Deus (cf. Fiorin), para construir o seu. Em grande parte do Antigo Testamento, e também do Novo, percebemos que a ordem de Deus, e seus conselhos, seriam para que todo o povo de Israel esperasse nele, ou seja, descansasse em suas Palavras, cresse/confiasse em suas promessas. Podemos recuperar isso em exemplos notórios nos salmos e em algumas epístolas neotestamentárias: Esforçai-vos, e ele fortalecerá vosso coração, vós todos que esperais no Senhor (Sl 31,24)/ Descansa no Senhor, espera nele... (Sl 37,6)/ ...Espera em Deus... (Sl 42,5/43,5)./ Esperai inteiramente na graça que se vos ofereceu na revelação de Jesus Cristo (I Pe 1, 13). (SANTANA, 2015, p. 9).

Assim, em meio a essa arena heterodiscursiva, confrontos dados nas fronteiras do dizer como réplica, Jesus pronuncia:

V. 46 Se crêsseis em Moisés, haveríeis de crer também em mim; porque foi a meu respeito que ele escreveu.

V. 47 Mas, se não credes em seus escritos, como crereis em minhas palavras? (João 5: 46-47).

As enunciações do sujeito mobilizam uma discursividade por meio de afronta, e se deslocam em declarações: caso verdadeiramente os judeus seguissem e vivessem a lei Mosaica (instituída por Deus), creriam também nele, emblema do Deus na terra (cf. João 1,1). Mais uma vez recorremos a Santana (2015), para quem, no escopo arquitetônico do Antigo Testamento, os judeus se certificavam de que na crença na Lei, encontrariam a Vida Eterna. Estes davam plena atenção ao conjunto do Pentateuco, conteúdo visível da Lei Mosaica. Porém, se buscassem praticar o conteúdo existente nos papiros referidos - instituídos por Moisés -, aceitariam o testemunho de Jesus, que vinha cumprindo toda a Lei.

Conforme se torna visível no domínio extra-estético do discurso bíblico, pelo fato de os judeus estarem reagindo adversamente aos posicionamentos éticos e morais de Jesus, estavam também mostrando repúdia pelas práticas de Moisés e dos profetas, os quais haviam prenunciado a vinda de Jesus e seu governo messiânico. Porque de mim escreveu ele. Acerca de Jesus, Moisés havia falado muitas vezes, prenunciando a sua vinda à terra, em enunciados que elencam inimizade (Gn 3.15), bênção familiar em Jesus (12. 3), poder eterno conferido ao Cristo (49.10) e o levante de um grande profeta (Dt 18.15-18). (SANTANA, 2015). 
Como poderiam crer naquele que libertou o povo de Israel do Egito, e não crer naquele que o fez libertar?5 Eis o princípio axiologicamente constitutivo do ceticismo judaico, mediante as enunciações de Jesus.

$\mathrm{Na}$ medida em que confrontam as palavras proferidas pelo sujeito enunciador Jesus, a liderança sacerdotal judaica tenta permanecer firme via os ditos outorgados pela legislação mosaica. Porém, quando os discursos de Moisés e de Jesus são postos em análise, atesta-se sua interrelação de concordância (cf. Bruce), pois há constantes atravessamentos e refigurações de um no outro. A rejeição a um significa estar se opondo ao outro. O que Jesus, enquanto sujeito responsável por suas dizibilidades, estava querendo atestar, era que não veio para anular as leis (neste caso, instituídas por Moisés) e os profetas, mas para cumpri-las (Mt 5. 17). Grande parte dos escritos do Pentateuco e dos evangelhos e cartas neotestamentárias confirmam posições axiológicas de complementaridade entre os discursos de Jesus e de Moisés.

\section{CONSIDERAÇÕES FINAIS}

Diante do escopo arquitetônico joanino via as réplicas de Jesus sobre o ceticismo judaico, podemos afirmar que tanto axiológica quanto heterodiscursivamente, a individualidade do sujeito enunciador é corporificada na agenda sócio-extra-verbal.

Como sujeito responsivo-ativo, aquele que é chamado o Cristo projeta-se dialogicamente na expressão (marcada) de seu querer-dizer, de seu concreto ideológico-discursivo, ao re(e)nunciar (a)o discurso judaico sobre a glorificação antropocêntrica. Conforme já mencionamos, as enunciações de Jesus materializam sua potencialidade argumentativa no que concerne à Lei Mosaica, o que subsidia historicamente seus ditos.

Jesus, na posição de enunciador de réplicas, para constituir sua discursivização, leva em conta o discurso de outrem, utilizando-o no seu. Essa nova enunciação, além de fazer emergir a terceira instância enunciativa, confere caráter de valoração à lei da

5 Acerca disso, podemos nos transpor para o último enunciado proferido por Abraão ao homem rico, de acordo com o relato de Lucas (16,31): "Se não ouvem a Moisés nem aos profetas, tampouco acreditarão, ainda que algum dos mortos ressuscite”. Ou seja, se a massa judaico-farisaica nem a sua própria lei de segmento (mosaica) cumpre, muito menos prestaria ouvidos aos milagres realizados por Cristo. 
Graça, em que Cristo reage responsiva e responsavelmente a um sistema político individualista e egocêntrico: o judaico-farisaico.

Apesar de confrontar outros discursos fortes e hegemônicos que escravizavam as pessoas naquele contexto sócio-histórico, Jesus propôs, por meio de recursos de linguagem, 'desfazer' a base de argumentação dos líderes judaizantes. Interpôs-se nas fronteiras ético-cognitivas mosaico-levíticas e reacentuou as possibilidades do viver persuasivamente cético.

\section{REFERÊNCIAS}

BAKHTIN, Mikhail M. Estética da Criação Verbal. [tradução feita a partir do russo; tradução Paulo Bezerra]. 5. ed. São Paulo: Martins Fontes, 2006 [1979].

BAKHTIN, Mikhail M. Os gêneros do discurso. Tradução, posfácio e notas de Paulo Bezerra. São Paulo: 34, 2016 [1979].

BAKHTIN, Mikhail M. O problema do Conteúdo, do Material e da Forma na Criação Literária. (1924). In: Questões de literatura e de estética - A Teoria do Romance. Equipe de tradução (do russo) Aurora Fornoni Bernardini; José Pereira Júnior; Augusto Góes Júnior; Helena Spryndis Nazário; Homero Freitas de Andrade. $6^{\mathrm{a}}$ edição. Editora Hucitec - São Paulo, 2010 (1930-1934).

BAKHTIN, Mikhail M. Questões de literatura e de estética - A Teoria do Romance. Equipe de tradução (do russo) Aurora Fornoni Bernardini; José Pereira Júnior; Augusto Góes Júnior; Helena Spryndis Nazário; Homero Freitas de Andrade. $6^{\mathrm{a}}$ edição. Editora Hucitec - São Paulo, 2010 (1930-1934).

BAKHTIN, Mikhail M. Teoria do romance I: a estilística. Tradução, prefácio, notas e glossário de Paulo Bezerra; organização da edição russa de Serguei Botcharov e Vadim Kójinov. São Paulo: Editora 34, 2015.

BARROS, Diana Luz Passos. Contribuições de Bakhtin às Teorias do Discurso. In: BRAIT, B. (Org). Bakhtin, dialogismo e construção de sentido. Campinas/SP: Editora UNICAMP, 2005.

BECHARA, Evanildo. Moderna Gramática Portuguesa. $37^{\mathrm{a}}$ edição revisada, ampliada e atualizada conforme novo acordo ortográfico. Ed. Nova Fronteira: Rio de Janeiro, 2009.

BÍBLIA SAGRADA (Bíblia de Jerusalém). Tradução do texto em Língua Portuguesa diretamente dos originais. Nova Edição Revista e Ampliada. $1^{\text {a }}$ edição. Paulus Editora, São Paulo, 2002. 
BRUCE, F.F. João - Introdução e comentário. Série Cultura Bíblica; Tradução de Hans Udo Fuchs. Editora Vida Nova; São Paulo, 2011.

CHAMPLIN, Russel Norman. Enciclopédia de Bíblia, Teologia \& Filosofia. Vol. 3. $12^{\circ}$ edição. Direitos de tradução reservados à Editora Hagnos. São Paulo, 2014 .

MEDVIÉDEV, Pável Nikoláievitch. O Método Formal nos estudos literários: introdução a uma poética sociológica. Tradutoras: Sheila Camargo Grillo e Ekaterina Vólkova Américo. São Paulo: Contexto, 2012 [1928].

PONZIO, Augusto. A Revolução Bakhtiniana: o pensamento de Bakhtin e a ideologia contemporânea. Coordenação de tradução de Vladmir Miotello. São Paulo: Contexto, 2008.

RENFREW, Alastair. Mikhail Bakhtin. Tradução de Marcos Marcionillo. $1^{\mathrm{a}}$ ed. São Paulo: Parábola, 2017.

ROCHA LIMA, Carlos Henrique da. Gramática Normativa. $33^{\text {a }}$ edição. José Olympio editora; Rio de Janeiro, 1972.

SANTANA, Wilder Kleber Fernandes de. A autoria e a responsabilização linguística, enunciativa e discursiva de Jesus Cristo em "a parábola do semeador", a partir do Evangelho segundo Mateus. In: XVII Congresso Internacional Associación de Lingüística y Filología de América Latina (ALFAL) - Anais. Organização: CCHLA. Universidade Federal da Paraíba. - João Pessoa, 2014. p. 1-12.

SANTANA, Wilder Kleber Fernandes de. A autoria e a responsividade linguística e discursiva de Jesus Cristo em sua exposição acerca do Sal da terra e da Luz do mundo, a partir do evangelho segundo Mateus. In: II Congresso Nacional de Literatura (CONALI) - Anais. Organização: ARAGÃO, Maira do Socorro Silva de. et al. Universidade Federal da Paraíba. - João Pessoa, 2014. p. 591 - 600.

SANTANA, Wilder Kleber Fernandes de. Heterodiscursividade e Axiologia no primeiro capítulo do Cântico Dos Cânticos. In: SINALP - Simpósio Nacional de Literatura Popular, 2017, Joao Pessoa. Cultura Popular e Cosmopolitismo - Simpósio Nacional de Literatura Popular. Joao Pessoa: Mídia Editora, 2017.v. 1. p. 6-247.

SANTANA, Wilder Kleber Fernandes de. Jesus Cristo e seu discurso acerca da incredulidade judaica: uma representação dialógico-discursiva a partir do relato do evangelista João. IX SELIMEL - Seminário Nacional sobre Ensino de Língua Materna e Estrangeira e de Literatura. Anais eletrônicos. ISSN: 235709765. UFCG, 2015 .

SEGALLA, Domingos Paschoal. Novíssima Gramática da Língua Portuguesa. 48 a edição revisada. Cia Editora Nacional; São Paulo, 2008. 
VINE, W. E.; UNGER, Merril F.; WHITE JR, William. Dicionário Vine - o significado exegético e expositivo das palavras do Antigo e do Novo Testamento. Tradução de Luís Aron de Macedo. CPAD; Rio de Janeiro, 2013.

VOLOCHÍNOV, Valentin Nikolaevich. (círculo de Bakhtin). Marxismo e filosofia da linguagem - Problemas fundamentais do método sociológico na ciência da linguagem. Tradução de Sheila Grillo e Ekaterina Vólkova Américo - Ensaio introdutório de Sheila Grillo. $1^{\mathrm{a}}$ ed. São Paulo: Editora 34, 2017 [1929].

Recebido em: 21.07 .2018 Aprovado em: 16.12 .2018 